\title{
Perspective Piece Who Will Pay for the COVID-19 Vaccines for Africa?
}

\author{
Don Eliseo Lucero-Prisno III $^{1}$ Isaac Olushola Ogunkola, ${ }^{2 *}$ Uchenna Frank Imo, ${ }^{2}$ and Yusuff Adebayo Adebisi ${ }^{3}$ \\ ${ }^{1}$ Department of Global Health and Development, London School of Hygiene and Tropical Medicine, London, United Kingdom; ${ }^{2}$ Department of \\ Public Health, University of Calabar, Calabar, Nigeria; ${ }^{3}$ Faculty of Pharmacy, University of Ibadan, Ibadan, Nigeria
}

\begin{abstract}
Africa's health systems are strained by the COVID-19 pandemic. There are global efforts toward the development and trial of COVID-19 vaccines. However, considering the challenges and economic conditions of African nations, there could be limited access and availability of the vaccines on the continent. This will be the result of high cost and technical requirements to acquire the vaccines. There are indications that possible donor funding for COVID-19 vaccines from rich countries maybe put off considering the various challenges they face currently and the moves they are making in response to the disease. The issue of justice in health for protecting the vulnerable populations and regions also supports the need for COVID-19 vaccine availability on the African continent. Means to achieve uniform control of the disease burden across the globe should be adopted. Governments of African nations should also scale up their efforts toward COVID-19 vaccine acquisition and utilization through viable efforts. It is therefore important to assist the African continent in acquiring the COVID-19 vaccines by leveling all power dynamics that will affect access and distribution.
\end{abstract}

\section{INTRODUCTION}

Africa's health systems have been characterized weak because of shortage of human resources for health and overstressed healthcare facilities caused by lingering disease burden. The sudden upsurge in the number of SARS-CoV-2 cases and the rapid geographical expansion of the virus is further straining the system. ${ }^{1}$ Over the years, battles have been fought across the continent to eradicate diseases that contribute massively to morbidity and mortality rates. Plans, strategies, and various interventions have been carried out in Africa to curb many public health threats. ${ }^{2}$ The role of vaccines in mitigating disease morbidity and mortality around the globe cannot be overemphasized. This stems from the protection from target diseases that vaccines offer to population at risk.

Having a vaccine for COVID-19 would assist in the fight against the disease. This would also not be possible without ensuring availability, accessibility, and affordability of the vaccines for all regions of the world. Considering the possibility of having a vaccine and the necessity for Africa as a continent to access and use it, the pertinent question remains: Who will pay for Africa? African countries in the past have experienced inequity with antiretroviral drugs, leading to death of millions of Africans in the past. ${ }^{2}$ This past experience warrants the panic of African governments over what COVID-19 vaccines have to offer.

This article describes the current state and effort of developing and distributing vaccines globally, analyzed the possible reasons why Africa will not benefit adequately from the development, and addresses possible ways the vaccines will reach the continent.

\section{CURRENT EFFORTS ON VACCINE}

As an effective public health tool, vaccines have been shown to be the most successful measures for saving millions of lives against disease threat, especially when they are

${ }^{*}$ Address correspondence to Isaac Olushola Ogunkola, Department of Public Health, University of Calabar, Calabar, Nigeria. E-mail: isaacson.olushola@gmail.com implemented and carried out as programs effectively. ${ }^{3,4}$ In different countries of the world, vaccines have been the most effective measures in reducing morbidity and deaths associated with some diseases, especially killer diseases of children, for example, polio. Amid the responses of African governments to COVID- $19,{ }^{5}$ there have been efforts toward the production of a vaccine for the disease in some countries. Some high-income countries (HICs) have made some level of progress in vaccine production as most are already on trial phases, whereas others are almost ready. ${ }^{6}$

As of December 27, 2020, Oxford/AstraZeneca, Moderna, Pfizer/BioNTech, and Gamaleya (Sputnik V) COVID-19 vaccine candidates have shown some efficacy after the phase 3 clinical trials. This therefore confirms that global efforts are being channeled toward the production and dissemination of COVID-19 vaccine across the globe in the shortest time. However, beyond cost of the COVID-19 vaccines, many African countries will also face major logistical barriers for widespread implementation and delivery with the mRNA vaccines made by Moderna and Pfizer/BioNtech. The only other vaccine with published efficacy data, Oxford/AstraZeneca, has lower efficacy than Moderna and Pfizer/BioNtech, but with significantly lower costs and barriers for implementation. This raises an ethical dilemma: Should African countries have to "settle" for a lower efficacy vaccine, but which is much better suited for delivery given the specific constraints in those environments? Insisting on full equity (i.e., the higher efficacy mRNA vaccines) may actually mean lack of delivery in the near and mid (2021 and beyond) horizon; by which time, the need for a vaccine may well be lower because of unmitigated spread of COVID-19. It is important to note that infectious diseases are transcontinental and notwithstanding the credible efforts of these countries, and there is need to make provisions for equitable access and supports for effective delivery of the COVID-19 vaccines across all countries. This is key to the world's recovery from the pandemic. ${ }^{6}$

The development and trial of COVID-19 vaccine have become a key issue of funding and response in Africa. ${ }^{7}$ This is as a result of several challenges faced by the continent's health systems in response to COVID-19 among other diseases. Considering the journey of Africa in the war on previous and 
ongoing epidemic, vaccines have always reached the continent after these diseases have claimed the lives of thousands. There is a great possibility of history repeating itself if care is not taken. ${ }^{8}$ Some trial phases of COVID-19 vaccine are being carried out in Africa. ${ }^{7}$ The major motive for the trials in the continent has been to find out if the vaccine works in the African setting. ${ }^{6}$ In a bid to address the possible inequality that may arise between HICs and low- and middle-income countries (LMICs) in acquiring COVID-19 vaccines, the World Bank's Board of Executive Directors has approved $\$ 12$ billion fund to aid the developing countries in acquiring vaccines projected to reach a billion people. ${ }^{9}$ China who has at least four vaccine candidates has partnered with the COVID-19 vaccine Global Access Facility (COVAX) initiative-an initiative that promises to benefit Africa-to increase the reach of vaccines to all continents.

\section{WHO WILL PAY FOR AFRICA?}

There are indications that Africa will not access the vaccines as needed and on time because of several constraints faced by their health systems. Such indications are seen evident from the problems the health systems face in response to disease outbreak. Over the years, reports have shown the inability of Africa to comfortably acquire vaccines due to the high cost. Most, if not all African countries, fall into the category of $\mathrm{LMICs}^{6}$ with other typical African challenges like poor infrastructure, shortage of health workforce, diverse religion, and random distribution of population densities, ${ }^{10}$ combined with ongoing conflicts and displacements of people. Vaccine research and development are seldom headed by African countries which greatly affect their ability to acquire the vaccines they need.

The African continent has an estimated population of more than 1.2 billion people. With the recent spread of the virus on the continent, more than $1,528,000$ people have been infected and more than 36,828 dead. ${ }^{11}$ This is against the global figure of more than $35,848,000$ infected persons and 1,048,000 dead. ${ }^{11}$ There should be sufficient supply of vaccine to cater for a good proportion of the continent's poor, sick, and vulnerable populations. Provisions for storage of the vaccine for cases of subsequent vaccination through vaccination programs will also be necessary. These figures expose the extent to which the need for adequate provision of vaccines in the continent can be rated as when compared with other continents of the world. With Africa constituting $16.7 \%$ of the world's population, the continent must compete with other regions of the world for access to the COVID-19 vaccines.

Many HICs that could possibly donate vaccines to the African continent are currently under serious strains from the rage of the pandemic. This may limit the chances of assisting poor countries, which are majorly African nations in accessing COVID-19 vaccines. Most HICs have made provisions for vaccines ${ }^{8}$ before the call for the equitable access of vaccines. The issue of nationalism over universal health coverage ${ }^{12}$ comes to play as these countries have made early arrangements for the quantities of the vaccine that they would need, a move that ultimately stiffens the rate of production of the vaccine that will reach the most vulnerable groups in the least possible time. ${ }^{13}$ African countries rely on HICs that produce these vaccines to curb the prevalence of diseases on the continent. ${ }^{4}$ Because of the difference in the economic settings of HICs and LMICs, and with the production of vaccines in HICs by pharmaceutical companies ${ }^{12}$ and research laboratories, the cost of purchasing those vaccines is usually expensive for most African countries. Nigeria, a typical African country and the most populated, has a high level of undervaccination due to several challenges, which majorly indicates high cost of vaccine. ${ }^{14}$ Also, in past years, vaccination gets to the rural communities in Africa late and even COVID-19 intervention programs did not get to rural communities early. ${ }^{15}$

Considering the challenges faced by possible donor countries of COVID-19 vaccines, there are chances that poor nations may not be assisted in assessing the vaccines in the least possible time. ${ }^{8,13}$ Rich countries place precedence on meeting their health needs. Some reports have shown that most of these nations have agreed deals to secure vaccines for their citizens. ${ }^{8,12}$ Most of these deals are tied with the pharmaceutical companies. ${ }^{12}$ These countries will obviously place priority on their needs. Reports have shown the rise in the expenses made by donor countries. Several countries have made deals which have involved huge financial commitments ${ }^{8}$ toward responding to COVID-19 and the acquirement of vaccines when ready. This drags these poor nations out of the list of priorities by the donor countries. ${ }^{8}$

The recent legacy of Africa in eradicating polio ${ }^{3}$ shows the achievement of the continent's health systems from the interventions. Over the years, there have been records of increased number of trained health workers, social mobilizers, laboratorians, and vaccinators for polio. The health systems have improved as they gear toward safeguarding populations from vaccine-preventable diseases, carrying out routine vaccination plan and enhanced emergency diseases responses. $^{2,4}$ The same can be achieved in responses to COVID-19 on the continent. These achievements were supported by the vaccination programs set up in response to the disease spread. Even if vaccines are funded for these poor countries by the donor countries, there will be a need to set up vaccination program including other logistical requirements in these countries. This introduces a new dimension of challenge that will be faced even if vaccines for poor African nations are funded. The situation where the burden of COVID-19 and access to vaccines still lags in Africa will remain an issue of global health concern if nothing is done to aid the continent. Equitable access to COVID-19 vaccine and universal health coverage calls for interventions and global intervention on the continent. $^{16}$ This will result in accelerated and uniform recovery from the pandemic across the globe. The issue of justice in health for protecting the vulnerable population and regions $^{6,16}$ also supports the need for COVID-19 vaccine availability in Africa.

\section{RECOMMENDATIONS}

Considering the recent involvement and partnership among countries to develop and distribute vaccines for COVID-19, more countries should be encouraged to partner and contribute. Bodies like GAVI, the Vaccine Alliance should ensure cooperative, collaborative, and monopoly-free mechanism for the equitable access of the COVID-19 vaccines. ${ }^{4,12,13}$ This includes rich countries with high per-capital income and technological advancement. Similar achievement recorded in polio eradication in Africa can be achieved in a shorter period of time. ${ }^{3}$ The recent assembly of wealthy nations in COVAX 
should aim at promoting inclusion and equitable access to the vaccine for all African nations. ${ }^{6}$ In addition, the vulnerable, underrepresented, and the marginalized populations must not be forgotten in the vaccination program. ${ }^{13}$ There should also be increased collaboration between major stakeholders in the fight against the pandemic. This includes the government, researchers, manufacturers, and multilateral partners. ${ }^{6,7}$ Countries with high per-capital income should aid African countries with funding through health bodies such as the WHO. ${ }^{8}$ Governments of African nations should upscale efforts toward COVID-19 responses in terms of funding, data generation and projections, and national coordination of the vaccination program. Their involvement toward the global partnership for COVID-19 vaccines portfolio will be highly encouraged. The governments in Africa should own up and support local scientists and secure partnership to scale up vaccine research on the continent.

\section{CONCLUSION}

The disease burden for Africa will linger longer than expected if certain interventions and assistances are not initiated for the continent. Although there have been commitments from countries and organizations to help developing nations, more efforts are needed. The successful fight against the pandemic can be achieved through a strong cooperation between nations in addressing any inequity in vaccine access. It is therefore important to assist the African continent in acquiring the COVID-19 vaccines by leveling all power dynamics that will affect access and distribution. There is also a need for upholding pan-African goals and for the continent's governments to own up to their responsibilities and explore indigenous innovations toward controlling COVID-19 in Africa, and, hopefully, Africa may end up paying for Africa.

Received November 24, 2020. Accepted for publication December 28, 2020.

Published online January 7, 2021.

Acknowledgments: We appreciate the reviewers for their insightful comments. The American Society of Tropical Medicine and Hygiene has waived the Open Access fee for this article due to the ongoing COVID-19 pandemic and has assisted with publication expenses.

Disclosure: We have completed the ICMJE unified competing interest form (available upon request from the corresponding author).

Authors' addresses: Don Eliseo Lucero-Prisno, Department of Global Health and Development, London School of Hygiene and Tropical Medicine, London, United Kingdom, E-mail: don-eliseo.luceroprisno@Ishtm.ac.uk. Isaac Olushola Ogunkola and Uchenna Frank Imo, Department of Public Health, University of Calabar, Calabar, Nigeria, E-mails: isaacson.olushola@gmail.com and frankuche446@ gmail.com. Yusuff Adebayo Adebisi, Faculty of Pharmacy, University of Ibadan, Ibadan, Nigeria, E-mail: adebisiyusuff23@yahoo.com.

This is an open-access article distributed under the terms of the Creative Commons Attribution (CC-BY) License, which permits unrestricted use, distribution, and reproduction in any medium, provided the original author and source are credited.

\section{REFERENCES}

1. Adebisi YA, Oke GI, Ademola PS, Chinemelum IG, Ogunkola IO, Lucero-Prisno DE III, 2020. SARS-CoV-2 diagnostic testing in Africa: needs and challenges. Pan Afr Med 35: 4-14.

2. Nkengasong JN, Ndembi N, Tshangela A, Raji T, 2020. COVID-19 vaccines: how to ensure Africa has access. Nature 586: 197-199.

3. Adebisi YA, Eliseo-Lucero Prisno D III, Nuga BB, 2020. Last fight of wild polio in Africa: Nigeria's battle. Public Health Pract 1: 100043.

4. Ikilezi G, Augusto OJ, Dieleman JL, Sherr K, Lim SS, 2020. Effect of donor funding for immunization from Gavi and other development assistance channels on vaccine coverage: evidence from 120 low- and middle-income recipient countries. Vaccine 38: 588-596.

5. Lucero-Prisno DE, Adebisi YA, Lin X, 2020. Current efforts and challenges facing responses to $2019-n C o V$ in Africa. Glob Health Res Policy 5: 21.

6. WHO, 2020. 172 Countries and Multiple Candidate Vaccines Engaged in COVID-19 Vaccine Global Access Facility. Geneva, Switzerland: World Health Organization. Available at: https://www.who.int/news/item/24-08-2020-172-countriesand-multiple-candidate-vaccines-engaged-in-covid-19-vaccineglobal-access-facility. Accessed August 24, 2020.

7. Makoni M, 2020. COVID-19 vaccine trials in Africa. Lancet Respir 20: S2213-S2600.

8. Edward-Ekpu U, 2020. Most of Africa Will Not Have Access to COVID-19 Vaccines for up to a Year After Approval. Quartz Africa. Available at: https://qz.com/africa/1889305/most-ofafrica-wont-have-new-covid-19-vaccines-for-a-year/. Accessed December 24, 2020.

9. World Bank, 2020. World Bank Approves \$12 Billion for COVID-19 Vaccines. Available at: https://www.worldbank.org/en/news/ press-release/2020/10/13/world-bank-approves-12-billionfor-covid-19-vaccines. Accessed December 15, 2020.

10. Endurance AO, Musa YT, Azuka VA, Rachael O, Precious El, 2014. Current trends of immunisation in Nigeria: prospects and challenges. Trop Med Health 42: 67-75.

11. ECDC, 2020. COVID-19 Update Worldwide. European Centre for Diseases Prevention and Control Website. Available at: www.ecdc.europa.eu. Accessed October 8, 2020.

12. Prabhala A, Elder K, 2020. How will the world's poorest people get a coronavirus vaccine? The Guardian. Available at: https:// www.theguardian.com/commentisfree/2020/jun/24/worlds-poorestpeople-coronavirus-vaccine-gavi. Accessed December 3, 2020.

13. Shah S, 2020. In Race to Secure COVID-19 Vaccines, World's Poorest Countries Lag behind. Available at: https://www.wsj.com/articles/inrace-to-secure-covid-19-vaccines-worlds-poorest-countrieslag-behind-11598998776. Accessed December 27, 2020.

14. Elder K, 2013. Vaccine prices: a painful shot for Africa. OECD Observer (No. 296). Available at: https://oecdobserver.org/ news/fullstory.php. Accessed October 7, 2020.

15. Ogunkola IO, Adebisi YA, Imo UF, Odey GO, Esu E, Lucero-Prisno DE III, 2020. Rural communities in Africa should not be forgotten in responses to COVID-19. Int J Health Plann Manage 35: 1302-1305.

16. Adebisi YA, Ekpenyong A, Ntacyabukura B, Lowe M, Jimoh ND, Abdulkareem TO, Lucero-Prisno DE, 2020. COVID-19 highlights the need for inclusive responses to public health emergencies in Africa. Am J Trop Med Hyg. doi: 10.4269/ajtmh.20-1485. 